\title{
VIABILIDADE DA IMPLANTAÇÃO DE UMA INDÚSTRIA PRODUTORA DE HIDROMEL
}

\section{VIABILITY OF THE INTRODUCTION OF A PRODUCING INDUSTRY OF HYDROHONEY}

\author{
Jéssica Pestrini Nakada - je.nakada@hotmail.com \\ Lidia Urbano Caciatori - lidia_urbano@hotmail.com.br \\ Marcos Alberto Cláudio Pandolfi - marcos.pandolfi@fatectq.edu.br \\ Faculdade de Tecnologia de Taquaritinga (Fatec) - Taquaritinga - São Paulo - Brasil
}

DOI: 10.31510/infa.v17i1.789

\section{RESUMO}

O presente artigo teve por objetivo abordar a viabilidade da implantação de uma indústria de produção de hidromel, bebida antiga produzida a partir da fermentação do mel, dotada de raízes históricas. Para tanto, foi realizado levantamento e posterior revisão bibliográfica, buscando informações acerca da indústria e do produto em questão, para que posteriormente fosse elaborado um plano de negócios. Foi realizada, ainda, a análise estratégica e de mercado, com o objetivo de identificar os aspectos externos à empresa, tais como concorrência, clientes e fornecedores, bem como, os aspectos internos da empresa produtora de hidromel, apontando os pontos fortes e os riscos intrínsecos ao produto e às condições de desenvolvimento, assim como a legislação pertinente, os equipamentos necessários, os custos e receitas, analisando os investimentos necessários ao desenvolvimento do plano de negócios proposto. Ao final, foi analisada a viabilidade econômica, onde foi possível concluir que o empreendimento se mostra viável para altos volumes de produção.

Palavras-chave: Hidromel. Plano de Negócio. Análise Estratégica. Efetividade Econômica.

\begin{abstract}
The present article had since objective boarded the viability of the introduction of an industry of production of hydrohoney, ancient drink produced from the fermentation of the honey, endowed of historical roots. For so much, lifting and subsequent bibliographical revision was carried out, looking for informations about the industry and the product open to question, so that subsequently a business plan was prepared. The strategic analysis was carried out, still, and of market, with the objective of identifying the extern aspects to the enterprise, such as competition, clients and suppliers, as well as, the internal aspects of the producing enterprise of hydrohoney, pointing to the strong points and the intrinsic risks to the product and to the conditions of development, as well as the relevant legislation, the necessary equipments, the costs and receipts, analysing the necessary investments to the development of the proposed plan of business. To the end, study of economical viability was carried out, where it was possible to end what the undertaking shows viable for high production volumes.
\end{abstract}


Keywords: Hydrohoney. Business plan. Strategic analysis. Economical Efectivity.

\section{INTRODUÇÃO}

Atualmente, o mercado tem demonstrado forte interesse por bebidas fermentadas de produção artesanal em nosso país, um grande exemplo, é a difusão e a comercialização de cervejas artesanais. Esse cenário se mostra positivo à exploração e comercialização do hidromel, pois, embora a bebida seja pouco consumida no Brasil, contando apenas com produções domésticas, em outros países como os Estados Unidos da América, encontra-se em franca expansão.

Assim, atentando-se a potencialidade do produto, o presente trabalho foi desenvolvido com a finalidade de analisar a viabilidade de um plano de negócios de uma produtora de hidromel, fornecendo um panorama do mercado e analisando a viabilidade econômicofinanceira do negócio. A ideia do Plano de Negócios é guiar o planejamento e a operação de um empreendimento, pois ao seu basear em dados e informações, o plano de negócios pode fornecer uma ideia do resultado do negócio, antecipando os riscos do empreendimento (CHIAVENATO, 2005).

A escolha da temática se justifica, pois, o mercado de produtos artesanais encontra-se em franca expansão e, por isso, a produção de hidromel, se aliada a um plano de negócios eficaz, pode gerar resultados positivos.

\section{FUNDAMENTAÇÃO TEÓRICA}

\subsection{O Hidromel}

O hidromel é uma bebida alcoólica fermentada, produzia à base de mel, contendo entre 08 e $18 \%$ de etanol, caracterizando-se por ser uma bebida nutritiva, que contém muitos elementos necessários ao organismo, possuindo efeito positivos para digestão e metabolismo. A bebida pode conter frutas e especiarias, mas continua caracterizado se a maior parte do açúcar fermentado vier do mel (TOUSSAINT-SAMAT, 2009). 
O hidromel é uma bebida alcoólica fermentada, produzida a base de mel, contendo entre 08 e $18 \%$ de etanol, caracterizando-se por uma bebida nutritiva, que contém muitos elementos necessários ao organismo, possuindo efeitos positivos para digestão e metabolismo. A bebida pode conter frutas e especiarias, mas continua caracterizando-se na maior parte pelo açúcar fermentado proveniente do mel. (TOUSSAINT-SAMAT, 2009).

O hidromel tradicional pode apresentar características de mel silvestre, onde o mel não tem origem de uma flor específica, ou de misturas de méis como o de flor de laranjeira e eucalipto. Ainda podem ser feitos com apenas um tipo específico de mel, sendo caracterizado como varietal. Dentre as diversas características, os estilos podem ser definidos como hidromel seco, semi-doce e doce. (PUCCINELLI, 2018)

Apesar de ser muito comparado com cervejas, o hidromel tem uma composição muito mais parecida com a do vinho, o hidromel seco é extremamente similar ao vinho branco seco. Ele possui uma nuance de mel e sabores frutados delicados. A complexidade dos sabores e a harmonia com a qual eles se desenvolvem são desejáveis nesse tipo de hidromel, a cor deve ser consistente assim como o aroma. (PUCCINELLI, 2018)

O hidromel semi-doce tem um equilíbrio parecido, final e intensidade de sabor como um vinho branco semi-seco, o sabor do mel, no entanto é mais aparente do que no hidromel seco. Resultando em um produto que, apesar de parecido, tem um sabor diferente de qualquer outra variação. (PUCCINELLI, 2018)

O hidromel doce leva uma mistura de caráter de mel, leve dulçor, ésteres frutados delicados e álcool limpo. Complexidade, harmonia e equilíbrio dos elementos sensoriais são altamente desejáveis, sem inconsistências de cor, aroma e sabor. (PUCCINELLI, 2018)

\section{$2.2 \mathrm{O}$ mercado do hidromel}

O hidromel é frequentemente considerado a bebida alcoólica mais antiga produzida pela humanidade, o ancestral das bebidas fermentadas, pois existem registros históricos que fazem referência à produção da bebida, de forma independente, na antiguidade, seja na Europa, Ásia ou África (TOUSSAINT-SAMAT, 2009).

Entretanto, a sua produção caiu em declínio com a difusão da produção de cerveja, proveniente dos grãos, e de vinho, proveniente das uvas, cujas produções apresentavam-se menos custosas (TOUSSAINT-SAMAT, 2009). 
Entretanto, nos últimos anos, a sua produção voltou a crescer, principalmente nos Estados Unidos da América, onde é possível se verificar um aumento significativo de produtos comerciais, esse crescimento vem sendo impulsionado pela difusão da chamada cultura geek ${ }^{1}$, onde muitos fãs da mitologia nórdica e de festivais medievais, apreciam o consumo da bebida (TOUSSAINT-SAMAT, 2009)

O mercado brasileiro, atualmente, apresenta um grande potencial de crescimento, os principais consumidores do hidromel são homens e mulheres numa faixa etária acima de 20 anos, o mercado está centralizado principalmente na parte sul e sudeste do Brasil, a maior parte das feiras acontece em São Paulo e Curitiba, sendo que grande parte das empresas e artesões que produzem a bebida estão localizados nestas regiões também.

Há uma grande demanda para compras online do produto, o que possibilita o envio para pessoas de todas as partes do Brasil desde que a empresa possua o porte para lidar com a demanda.

O nível sócio econômico dos clientes também e algo importante e que deve ser considerado, pois, atualmente, o hidromel é considerado uma bebida artesanal e, portanto, custosa de ser produzida e com grande valor agregado, apesar dos ingredientes serem muitas vezes simples o processo industrial realizado é custoso e demorado, sendo que algumas produções podem passar até 06 meses em processo de fermentação, sendo que o preço de uma garrafa de hidromel, de cerca de 1 litro, custa em torno de $\mathrm{R} \$$ 50,00 (cinquenta reais) no mercado, valor este que pode não ser considerado muito caro para um apreciador da bebida, mas para aqueles que nunca tiveram contato com a mesma, pode causar estranhamento.

Por isso, traçar um plano estratégico de negócios é a saída adequada, para que, dessa forma, possa-se garantir longevidade do empreendimento e extrair o maior lucro possível do produto.

Além disso, a empresa deve procurar produzir uma bebida de qualidade e que atraia o interesse dos consumidores, tendo em vista que estes procuram uma bebida suave e prazerosa de se apreciar, para tanto, deve-se investir nas etapas de fermentação, realizando investimentos focados na minimização do tempo gasto na fermentação preservando a qualidade do produto.

É preciso, ainda, que a empresa realize a chamada de cenário, objetivando assim um embasamento para suas estratégias.

\footnotetext{
${ }^{1}$ Geek é um anglicismo e uma gíria inglesa que se refere a pessoas peculiares ou excêntricas, fãs de tecnologia, eletrônica, jogos eletrônicos ou de tabuleiro, histórias em quadrinhos, livros, filmes e séries.
} 
Figura 1: Análise SWOT
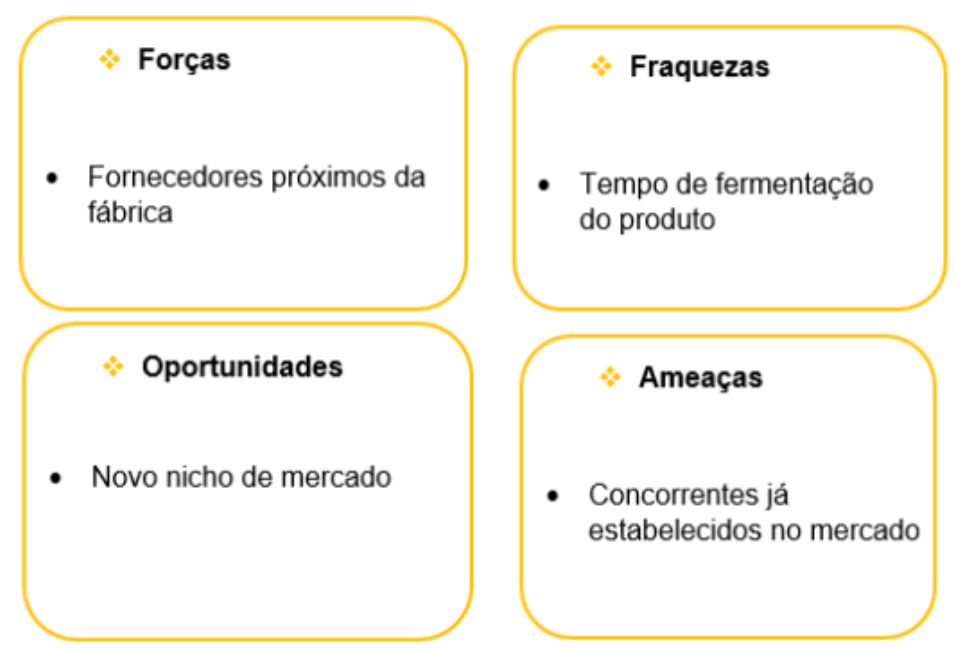

Fonte: Elaborada pelos autores.

A partir da análise SWOT, é possível elaborar as estratégias, as quais tem relação com o direcionamento da empresa, tanto na etapa de planejamento quanto de execução. Para Mintzberg (1988) a estratégia é um plano, um guia para as ações que serão tomadas no futuro, ou seja, é uma direção para chegar do ponto atual até o ponto desejado; e, estratégia é uma ação de fato tomada, com um padrão, ou seja, uma consistência de comportamento ao longo do tempo.

Para Porter (1980), toda empresa competindo em uma indústria tem uma estratégia competitiva, seja ela explícita ou implícita, sendo a essência dessa estratégia é a relação da empresa com o ambiente em que está inserida. Apesar de este ambiente ser bastante complexo, envolvendo forças econômicas e sociais, o autor propõe que o aspecto chave é a indústria em que a empresa está inserida, já que os outros aspectos, a princípio, afetam todos os concorrentes da indústria.

Desta forma, é fundamental analisar-se a indústria em que o negócio irá se inserir para, então, entender quais as características inerentes do empreendimento proposto para, finalmente, formular a estratégia pretendida para o mesmo. 
A implantação da indústria deve se valer, também, de um eficaz plano de marketing, o qual deve possibilitar o conhecimento do mercado, possibilitando que se trace o perfil do consumidor e que se tome decisões relativas a objetivos e metas, ações de divulgação e comunicação, preço, distribuição, localização do ponto de venda, produtos e serviços ofertados etc., enfim, ações voltadas à satisfação do público alvo (GOMES, 2005).

Para tanto, pode-se utilizar do plano de marketing dos 4 P's, o qual se baseia no preço, na praça, na promoção e no produto. (GOMES, 2005).

\section{PROCEDIMENTOS METODOLÓGICOS}

O presente artigo foi desenvolvido com base nas pesquisas em sites a respeito da produção de Hidromel, bem como em livros e artigos que abrangem a temática da produção e desenvolvimento de planos de negócio e administração.

A pesquisa foi dividida em duas principais etapas, além das conclusões, sendo elas a revisão bibliográfica pertinente ao tema, com o intuito de buscar conceitos e práticas já observadas na literatura existente, dando maior suporte ao restante do trabalho; e, a elaboração do plano de negócios, com a análise do nicho de mercado e elaborar o plano de marketing além dos elementos intrínsecos e extrínsecos à empresa que se visa constituir, tais quais podem influenciar o sucesso do negócio.

\section{RESULTADOS E DISCUSSÃO}

Seguindo os conceitos de análise estratégica, análise SWOT e o plano de marketing 4P's, foi realizada análise do ambiente, para que, posteriormente, pudesse se compreender o mercado consumidor, identificando o público alvo e definindo, ao final, as estratégias a serem tomadas pela empresa, delineando o seu possível posicionamento no mercado, concluindo, ao final, acerca da viabilidade ou não da implantação da indústria.

\subsection{O ambiente}

O setor de hidromel no Brasil ainda é pequeno, havendo poucos produtores em larga escala, sendo marcado, principalmente, por produções ditas caseiras, ou seja, realizadas por 
pequenos produtores caseiros e apicultores, os quais buscam aproveitar o excedente de matéria prima (SEBRAE, 2015).

O consumo de hidromel no Brasil ainda é voltado a um nicho específico, composto por consumidores interessados em culturas antigas e assuntos afins (SEBRAE, 2015).

Por ser um produto relativamente novo em nossa cultura, no Brasil ainda não há informações específicas acerca do consumo de hidromel, o qual, geralmente, é enquadrado na categoria de "outras bebidas fermentadas", onde fica ao lado de bebidas como sidra, espumante e sangria (SEBRAE, 2015).

\subsection{Clientes}

No Brasil, os consumidores de hidromel, geralmente, são entusiastas de culturas antigas e curiosos por provar novas bebidas. O primeiro nicho, é bastante restrito e pequeno, restringindo o mercado de atuação e, o segundo nicho, possui baixa taxa de reincidência de compra. Por isso, a exploração da bebida demanda a exploração de um novo setor de consumo (SEBRAE, 2015).

O hidromel pode se encaixar junto a sidra, encaixando a bebida no mundo do vinho, podendo ser facilmente ofertado aos clientes que consomem esse tipo de bebida.

É preciso, entretanto, que se trace um perfil do consumidor, o que pode ser realizado por meio da utilização do indicador do índice de conhecimento e do indicador do índice de congruência. O primeiro diz respeito ao nível de conhecimento do consumidor acerca da bebida e, o segundo, diz respeito a forma como o consumidor classifica a bebida, assim, pode-se chegar ao perfil do público alvo.

\subsection{O plano de marketing}

O plano de marketing adotado no presente trabalho, foi o denominado 4 P's (preço, praça, promoção e produto), onde o preço diz respeito ao valor que será gasto para produzir o produto, o qual não pode ser muito caro, haja vista que se trata de um mercado ainda não consolidado, devendo-se buscar pela colocação do produto no mercado consumidor.

A empresa localizar-se-á na cidade de Ibitinga, pois é um ponto forte de fornecedores e perto de outras cidades que também tem o mel, que é nosso ingrediente principal. 
A divulgação do produto será realizada por meio da internet, através da utilização de catálogo digital, divulgando o produto, ainda, em feiras e eventos característicos.

O produto será confeccionado de forma artesanal, aderindo aos gostos peculiares das pessoas, sendo confeccionado com ingredientes de qualidade, para ter um sabor excelente, de forma a conquistar e fidelizar clientes.

\subsection{A empresa}

A principal missão da empresa é manter a qualidade dos produtos valorizando e fidelizando a clientela, pois os clientes são os principais responsáveis por manter a empresa aberta e em expansão.

As vendas serão realizadas diretamente ao consumidor final, seja por meio do comércio via internet, seja através da participação em eventos e feitas temáticas, estudando-se, ainda, a possibilidade de abertura de uma loja própria.

A praça escolhida foi a cidade de Ibitinga-SP, pois é grande produtora de mel, contando, ainda com cidades circunvizinhas que produzem o produto, contando com mão-de-obra especializada, ofertando cursos para aperfeiçoamento de seus colaboradores. A princípio, a empresa contará com quatro colaboradores, os quais desempenharão funções administrativas, mão-de-obra, gerência e supervisão.

\subsection{O produto}

A produção do hidromel será realizada em onze etapas, primeiramente, será escolhido o mel e os nutrientes a serem utilizados, posteriormente, passa-se às etapas da mistura, fermentação, resfriamento, decantação, estabilização, clarificação, maturação, filtragem, engarrafamento e, por fim, a distribuição.

Para a confecção do produto, conta-se com a utilização de seis equipamentos essenciais, sendo eles o densímetro de 3 escaladas, destinado ao controle dos açúcares e à transformação dos mesmos em álcool, sendo utilizado em todas as etapas da produção; o termômetro digital, o qual permite a monitorar a temperatura da mistura; o fermentador, onde é depositado o mosto para que proceda à fermentação; airlock, que, em verdade, é uma válvula que impede a entrada de ar no fermentador e, ao mesmo tempo, permite a saída dos gases provenientes da 
fermentação; os sanitizantes, dotados de ação bacteriana, virucida, fungicida e esporicida, atuando como biofilmes dotados de poder de desinfecção; e, o refratômetro, equipamento utilizado para medir a quantidade de açúcares, densidade, umidade entre outras características do mel, possibilitando identificar se a umidade presente no mel e a quantidade de açucares estão e assim avaliar se o mel está adequado ou não para sua utilização na fabricação do hidromel.

\subsection{A legislação aplicável}

São aplicáveis à produção do produto a Portaria No 64, de 23 de abril de 2008, Anexo III; e, a Instrução Normativa MAPA N 34 DE 29/11/2012 a qual estabelece os padrões de qualidade para as bebidas fermentadas (fermentado de fruta; fermentado de fruta licoroso; fermentado de fruta composto; sidra; hidromel; fermentado de cana; e saquê ou sake), a qual estabelece os seguintes padrões de identidade e qualidade para o hidromel (Tabela 1).

Tabela 1: Padrões de Identidade e Qualidade para o Hidromel

\begin{tabular}{|c|c|c|c|c|}
\hline Item & Parâmetro & Limite Mínimo & Limite Máximo & Classificação \\
\hline 1 & Acidez fixa, em meq/L. & 30 & --------- & --------- \\
\hline 2 & Acidez fixa, em meq/L. & 50 & 130 & --------- \\
\hline 3 & Acidez fixa, em meq/L. & -------- & 20 & -------- \\
\hline 4 & Anidrido sulfuroso total, em g/L. & --------- & 0,35 & --------- \\
\hline 5 & Cinzas, em g/L. & 1,5 & --------- & --------- \\
\hline 6 & Cloretos totais, em g/L. & --------- & 0,5 & --------- \\
\hline 7 & Extrato seco reduzido, em $\mathrm{g} / \mathrm{L}$ & 7 & -------- & -------- \\
\hline 8 & $\begin{array}{l}\text { Graduação alcoólica, em \% v/v a } 20 \\
{ }^{\circ} \mathrm{C} \text {. }\end{array}$ & 4 & 14 & --------- \\
\hline \multirow{2}{*}{9} & \multirow{2}{*}{ Teor de açúcar em g/L. } & ---------- & $\leq 3$ & Seco \\
\hline & & $>3$ & --------- & Suave \\
\hline
\end{tabular}

Tabela retirada Instrução Normativa MAPA No 34 DE 29/11/2012. 
|WTERFAGET TECNOLOGGCA

\subsection{Investimentos e custos}

Tabela 2: Custos Fixos

\begin{tabular}{|c|c|c|c|c|c|}
\hline \multicolumn{6}{|c|}{ CUSTOS FLYOS } \\
\hline Item & Descriçao & \multicolumn{2}{|c|}{ Valor / mês } & \multicolumn{2}{|c|}{ Valor/ano } \\
\hline 1 & Agua* & RS & $1.320,00$ & $R S$ & $15.840,00$ \\
\hline 2 & Energia & RS & 600,00 & RS & $7.200,00$ \\
\hline 3 & Internet & RS & 100,00 & RS & $1.200,00$ \\
\hline 4 & Gás & RS & 150,00 & RS & $1.800,00$ \\
\hline 5 & Salário - administrativo & RS & $8.000,00$ & $R S$ & $96.000,00$ \\
\hline 6 & Salánio - mão de obra & RS & $2.400,00$ & $\mathrm{RS}$ & $28.800,00$ \\
\hline 7 & Saláuio - profissional TI & RS & $3.000,00$ & RS & $36.000,00$ \\
\hline \multirow[t]{2}{*}{8} & Site de vendas & RS & 50,00 & RS & 600,00 \\
\hline & TOTAL & & 20,00 & & 440,00 \\
\hline
\end{tabular}

*Considerando a compra mensal de galões de 20 litros

Fonte: Elaborada pelos autores.

Por definição, os custos variáveis são aqueles que ocorrem na proporção da quantidade produzida, ou seja, variam de acordo com o volume de produção.

Tabela 3: Custos Variáveis

\begin{tabular}{|c|c|c|c|c|c|c|c|c|}
\hline \multicolumn{9}{|c|}{ CUSTOS VARIÁVEIS } \\
\hline Item & Descriçao & Qtdade/mês & \multicolumn{2}{|c|}{ Valor unit. } & \multicolumn{2}{|c|}{ Valor Total/mês } & \multicolumn{2}{|c|}{ Valor Total/ano } \\
\hline 1 & Material de escritónio & 1 & RS & 200,00 & RS & 200,00 & RS & $2.400,00$ \\
\hline 2 & Embalagens & 1000 & RS & 0,50 & RS & 500,00 & RS & $6.000,00$ \\
\hline 3 & Rótulos & 1000 & RS & 0,80 & RS & 800,00 & RS & $9.600,00$ \\
\hline 4 & Rolhas & 1000 & RS & 0,30 & RS & 300,00 & RS & $3.600,00$ \\
\hline 5 & Ganafas (L) & 1000 & RS & 5,00 & RS & $5.000,00$ & RS & $60.000,00$ \\
\hline 6 & $\operatorname{Mel}(\mathrm{L})$ & 330 & RS & 25,00 & RS & $8.250,00$ & RS & $99.000,00$ \\
\hline 7 & Levedura 71B - 1122 (pac. 50g) & 60 & RS & 10,00 & RS & 600,00 & RS & $7.200,00$ \\
\hline 8 & Material sanitánio & 1 & RS & 100,00 & RS & 100,00 & RS & $1.200,00$ \\
\hline 9 & Luva descartável (caixa) & 1 & $\mathrm{RS}$ & 20,00 & RS & 20,00 & RS & 240,00 \\
\hline 10 & Máscara descartável (caixa) & 1 & RS & 15,00 & RS & 15,00 & RS & 180,00 \\
\hline \multirow[t]{2}{*}{11} & Touca descartável (caixa) & 1 & RS & 15,00 & RS & 15,00 & RS & 180,00 \\
\hline & & TOTAL & & & RS & $15.800,00$ & RS & $189.600,00$ \\
\hline
\end{tabular}

Fonte: Elaborada pelos autores.

A receita estimada com a execução do projeto foi formada pelas entradas em forma de recursos financeiros que o empreendimento receberá em cada mês, a partir da sua operação.

Tabela 4: Estimativa de Produção e Receita

\begin{tabular}{|c|c|c|c|c|c|}
\hline \multicolumn{6}{|c|}{ ESTIMLATIVA DE PRODUÇÁ / RECEITA } \\
\hline Item & Descriçao & Qtdade/mês & Preço de venda & Receita Mensal & Receita anual \\
\hline 1 & Hidromel $1 \mathrm{~L}$ & 1.000 & 50,00 & $50.000,00$ & $600.000,00$ \\
\hline & & & & RS $50.000,00$ & RS $600.000,00$ \\
\hline
\end{tabular}

Fonte: Elaborada pelos autores. 
As análises quantitativas referentes à decisão de investir são feitas a partir das projeções do projeto.

Segundo Oliveira (2007), um primeiro passo é a análise da rentabilidade que está relacionada aos investimentos, às receitas, aos custos e ao fluxo de caixa em um espaço de tempo. Os métodos indicados para esta análise são Payback, Taxa interna de retorno (TIR) e Valor presente líquido (VPL). O método de Payback é utilizado para informar o tempo de retorno do investimento, ao passo em que a TIR - Taxa Interna de Retorno é usada para tomar decisão de aceitar ou rejeitar o projeto. Caso a TIR seja maior que o custo de capital, aceita-se o projeto; se for menor, rejeita-se o projeto (OLIVEIRA, 2007).

O VPL é uma técnica de análise de orçamentos de capital, obtida subtraindo o investimento inicial de um projeto do valor presente das entradas de caixa descontada a uma taxa igual ao custo de capital da empresa. Geralmente, adota-se o critério de aceitar o projeto caso o VPL seja maior que 0 ; se for menor que 0 , rejeita-se o projeto (OLIVEIRA, 2007).

Após análise, foi possível chegar aos seguintes resultados:

Figura 2: Payback Simples

\section{PAYBACK SIMPLES \\ PAYBACK DESC.}

VPL

TIR

\section{RS $919.422,68$}

$35 \%$

Fonte: Elaborada pelos autores.

O que demonstra a viabilidade econômica do projeto, podendo o mesmo obter sucesso.

\subsection{DISCUSSÕES E RESULTADOS}

Considerando todos os dados levantados após o desenvolvimento desta pesquisa e após análise financeira detalhada, constatamos que uma produção de hidromel a nível industrial é possível, pois o mercado está em crescimento e a tendência é que continue assim. apurou-se que os gastos para produzir o hidromel com uma empresa de pequeno porte são relativamente baixos assim como o nível de investimento inicial, que fica em torno de quarenta mil reais com 
um espaço alugado ou em torno de quatrocentos e cinquenta mil considerando a aquisição de um espaço.

$\mathrm{O}$ caso analisado também tem a vantagem de ter fornecedores próximos à fábrica e, a venda dos produtos pela internet também é uma grande vantagem, pois abre portas para um mercado a nível nacional sem a necessidade de uma estrutura de entrega arrojada e também anula a necessidade de vendas físicas, diminuindo ou eliminando custos com viagens e combustível que os representantes utilizariam.

Outro ponto interessante é o tempo de retorno dos investimentos, que ocorreria em torno de três anos, o tempo baixo se dá pelo fato de que os lucros previstos para o projeto que seriam em torno dos cinquenta mil reais mensais dos quais vinte mil são lucros líquidos, um número impressionante para instalações pequenas como a analisada no projeto.

O projeto de uma fábrica de hidromel se mostra extremamente rentável, com um custo inicial baixo e com baixos riscos considerando a demanda do mercado, os equipamentos necessários para a fábrica podem ser adquiridos facilmente de múltiplos fornecedores o que também possibilita que o preço do investimento inicial seja ainda menor dependendo do fornecedor escolhido.

As instalações necessárias para o projeto podem ser pequenas e não produzem poluição sonora, o que também possibilita a busca de um local fora de áreas industriais, que tendem a ter aluguéis mais caros, o transporte realizado por terceiros também seria em sua maioria pago pelo cliente, o que é uma grande vantagem da venda pela internet.

\section{CONCLUSÃO}

Em conclusão, o projeto apresenta alto potencial de sucesso financeiro e de consolidar a marca como referência no mercado. Além de se apresentar como alternativa para agregar valor ao mel, expandir as estratégias de desenvolvimento territorial, fomentando o empreendedorismo, gerando emprego e geração de renda.

\section{REFERÊNCIAS}

CHIAVENATO, I. Gerenciando com as pessoas. Rio de Janeiro: Elsevier 2005. 
GOMES, I. M. Manual Como Elaborar um Plano de Marketing. Belo Horizonte: SEBRAE/MG, 2005.

MINTZBERG, H. Generic strategies: toward a comprehensive framework. In: SHRIVASTAVA, P. (Ed.). Advances in strategic management. Greenwich, Conn.: Jay Press, 1988. v.5. p.1-67.

MINISTÉRIO DA AGRICULTURA,PECUÁRIA E ABASTECIMENTO. Portaria n. 64, de 23 de abril de 2008. Diário Oficial da União de 24/04/2008, seção 1, p. 9. 2008.

Instrução Normativa MAPA $n^{0}$ 34, de 20 de novembro de 2011. Diário Oficial da União de 21/11/2012.

OLIVEIRA, D. P. R. Planejamento estratégico: conceitos, metodologia, práticas. 24. ed. São Paulo: Atlas, 2007.

PORTER, M. E. Competitive strategy: techniques for analysing industries and competitors. New York: Free Press, 1980.

SERVIÇO BRASILEIRO DE APOIO ÀS MICRO E PEQUENAS EMPRESAS (SEBRAE). Apicultura: relatório de inteligência, 2015. Disponível em: $<$ http://www.bibliotecas.sebrae.com.br/chronus/ARQUIVOS_CHRONUS/bds/bds.nsf/803afc f50b5e78c72c250aa49f1960c2/\$File/5384.pdf>. Acesso em: 02 abr. 2019.

TOUSSAINT-SAMAT, M. A history of food. New Expended Edition. Translate by Anthea Bell. Wiley-Blackwell: A Jhon iley \& Sons. Ltd. Publication, 2009.

PUCCINELli, F. Hidromel - Dicas Para Um Iniciante - Parte 1, 2018. Disponível em: $<$ https://www.lamasbrewshop.com.br/blog/2018/11/hidromel-parte-1.html> Acesso em: 19 mai. 2020

Pesquisa Sobre o Mercado de Hidromel, 2015. Disponível em: $<$ http://engenhariadacerveja.com.br/2015/05/04/pesquisa-sobre-o-mercado-de-hidromel/> Acesso em: 19 mai. 2020 